\section{Leprosy transmission in endemic and non-endemic areas based on the profile of antibody response of PGL-1 and PCR detection of Mycobacterium leprae DNA from nasal swab among healthy children of East Java, Indonesia}

\author{
Dinar Adriaty, ${ }^{1}$ Cita Rosita SP, ${ }^{1,2}$ \\ Iswahyudi, ${ }^{1}$ Ratna Wahyuni, ${ }^{1}$ \\ Indropo Agusni, ${ }^{1,2}$ Shinzo Izumi ${ }^{1}$
}

${ }^{1}$ Leprosy Study Group-Institute of Tropical Disease; ${ }^{2}$ Dermatology and Venereology, Medical Faculty Universitas Airlangga, Surabaya, East Java, Indonesia

\begin{abstract}
Background: East Java has become one of the provinces that have higher prevalence of leprosy, especially in the coastal region. Environment has also influenced for leprosy transmission and early detection could reduce the incidence rate of new leprosy cases. Epidemiological studies of leprosy in children can give an illustration of the important aspects of the environment. Presence of Mycobacterium leprae (M. leprae) DNA in nasal swabs and seropositivity level among them can describe M. leprae exposure in that area.
\end{abstract}

Objective: Analyzing PCR from nasal swab and seropositivity level among elementary school children between northern coast and southern coast of East Java province.

Methods: Five hundred and thirty children in Pacitan and Lamongan were involved. Both areas are representation of northern and southern coastal region in East Java Province. After clinical examination, nasal swab and blood samples were obtained. ELISA test was performed to measure the titer of IgM anti Phenolic Glicolipid-1 (PGL-1) antibody then continued by PCR to detect $M$. leprae DNA.

Results: From 301 students in Pacitan, 25 students $(8.3 \%)$ are sero-positives and 9 students $(2.9 \%)$ are PCR positives. from 229 students in Lamongan, 110 (48,3\%) students are sero-positives and 49 students (21.4\%) are PCR positives. Both are analyzed by Chi-Square, and from the PCR and ELISA, it concluded that there are statistically significant differences between the two regions.
Conclusion: From study above shows that in the northern coast of East Java, incidence of subclinical leprosy is still high, it means that in this area still has a high risk of new cases of leprosy in the future and early detection tools need to performed as a preventative measure.

\section{Introduction}

Leprosy is a chronic granulomatous disease cause by Mycobacterium leprae ( $M$. leprae). It is still become a major problem in Indonesia because it involves severe handicaps, social stigma, and economic loss. According to Global Leprosy Strategy 2016-2020, leprosy elimination focused on early case detection before visible disabilities occur. A special focus will be on children as a way to reduce disabilities and reduce transmission. The global target is zero disabilities among new pediatric leprosy patients by $2020 .^{1}$

Until the beginning of year 2000,generally, the prevalence of leprosy in Indonesia decreased according to the WHO target of $<1$ per 10,000 population, ${ }^{2}$ but the number of new leprosy patients has not decreased and clustered in several leprosy endemic areas called 'pockets areas' especially in eastern part of Indonesia. ${ }^{2,3}$ East Java is still the province with the highest leprosy patients, spread in 37 districts/cities. Leprosy endemic area in East Java were still clustered mostly in the north coast of East Java, while the south coast has a low prevalence. ${ }^{3}$ Indonesia is still reporting the existence of new leprosy with $84.5 \%$ of cases are Multi Basiler (MB) type of the new cases each year, $8.9 \%$ are children and of these child cases it is known that $6.7 \%$ of cases lead to disability. ${ }^{4}$ Environment has also had potential reservoir for leprosy transmission especially non-human factor, ${ }^{5}$ epidemiological studies of leprosy in children can give an illustration of the important aspects of the environment, in the patterns influence of leprosy transmission in endemic area because children have lower mobility than adults. ${ }^{6}$ Presence of M. leprae DNA in nasal swabs and immune response from seropositivity of IgM antibody anti PGL-1 spesific to M. leprae among elementary school children can describe Mycobacterium leprae exposure in that area. ${ }^{7-9}$ The purpose of the research to analyze seropositivity level and PCR from nasal swab among elementary school children between northern coast and southern coast of east java province that representative of leprosy and non leprosy endemic areas in East Java.
Correspondence: Dinar Adriaty, Institute of Tropical Diseases Universitas Airlangga, Jl. Mulyorejo Kampus C UNAIR Surabaya, Jawa Timur, 60115, Indonesia.

Tel.: +628165414604,

E-mail: ddriaty@yahoo.co.id dinadria@gmail.com

Key words: Mycobacterium leprae, DNA, phenolic glycolipid-1, children, Indonesia.

Contributions: The authors contributed equally.

Conflict of interest: The authors declare no potential conflict of interest.

Funding: The work was supported by a JICA silver expert program, LITSTRANAS grant from ministry of research technology and higher education Indonesia.

Acknowledgements: This work was supported by JICA silver expert program and LITSTRANAS grant from ministry of research technology and higher education Indonesia. We would like to express our gratitude to the investigators, researchers, coordinators, research assistants, Sutomo hospital Surabaya for all the support and ministry of health for East Java Province and all children as respondents and their family members, all teachers as well, both in Lamongan and Pacitan, East Java, Indonesia.

Clinical trials: No clinical trials

Conference presentation: This article has been presented an international conference Infectious Diseases, Biothreats, and Military Medicine (INSBIOMM).

Dedication: The article is dedicated to all children as respondents and their family members, all teachers as well, both in Lamongan and Pacitan, East Java, Indonesia.

Received for publication: 17 February 2020. Accepted for publication: 1 July 2020.

This work is licensed under a Creative Commons Attribution-NonCommercial 4.0 International License (CC BY-NC 4.0).

(C) Copyright: the Author(s), 2020

Licensee PAGEPress, Italy

Infectious Disease Reports 2020; 12(s1):8748

doi:10.4081/idr.2020.8748

\section{Materials and Methods}

\section{Collection of clinical specimens}

Samples were taken by purposive sampling, from 4th to 6th grade elementary school children. Healthy school children were taken from one village in the Lamongan district that represent the leprosy endemic area and one village in the Pacitan district, represent the leprosy non endemic 
area of East Java. The definition of healthy children includes those clinically showing no signs of leprosy during a physical examination (see Figure 1). ${ }^{10}$

\section{ELISA (Enzyme Linked Immunosorbent Assay)}

A total of $3 \mathrm{~mL}$ of blood serum isolated then proceed with the analsis of indirect ELISA. ELISA microplate well (Nunc, Maxisorp) were coated overnight with antigens, synthetic PGL-1 (50 ng/well NT-PBSA) antigen in $50 \mu \mathrm{l}$ carbonate/bicarbonate $0.1 \mathrm{M} ; \mathrm{pH} 9.6$ coating buffer. Blocking buffer consisting of $1 \%$ skimmed milk/ PBS and serum total diluted $1 / 300$ in $0.1 \%$ skimmed milk/ PBS/ Tween-20. Samples were analiyzed in duplo and incubated for an hour at $37^{\circ} \mathrm{C}$. The wells were washed with PBS-Tween20 and incubated with horseradish peroxidase conjugated antibodies (Dako, Denmark) diluted to $0.1 \%$ skimmed milk/PBS/Tween-20. The plates stained with substrate ortho-phenilendiamine (OPD) and 30\% peroxidase (MERCK) in phosphate-citrate buffer and incubated until developed a yellow color and stopped with $1.25 \mathrm{M} \mathrm{H}_{2} \mathrm{SO}_{4}$. Antibody IgM anti-NT-P-BSA were measured by optical density (OD) and converted automatically into unit/mL by BIOLISE software.

\section{DNA Isolation from Nasal Swab}

Nasal swab were taken by a sterilized cotton-tipped swab (mentip-Japan) that have been moistened with PBS and rubbing gently on the lateral and median sides of each nasal cavity. Sterilized distilled water $(0.5 \mathrm{~mL})$ was introduced in each $1.5 \mathrm{~mL}$ sterilized microtube and vortexed with the swab in place for $1 \mathrm{~min}$, then expressed the swab against the tube wall and squeeze it out then discarded. After removal of the cotton bud, the suspension was centrifuged in highspeed $\left(10,000 \mathrm{~g}\right.$; for $30 \mathrm{~min}$ in $\left.4^{\circ} \mathrm{C}\right)$ then take out the supernatant and keep the pellet. Resuspended the pellet with QIAprep spin miniprep kit cat.no.27106 from Qiagen.

\section{The PCR Nested Amplification}

DNA $M$. leprae detection performed using nested PCR to detect RLEP3 sequence X17153 target, spesific of M. leprae. The primers LP-F 5'TATCGATGCAGGCGTGAGTGT3' and LP-R 5'CTAACACGATACTGCTGCAC3'ampli fying $260 \mathrm{bp}$ DNA for external product (outer) and amplicon were then amplified again using primer LP-1 5'TGCATGTCATGGCCTTGAGG3' and LP-2 5'CACCGATACCAGCGGCAGAA3' for internal product (inner) 129 bp as a final product. ${ }^{11}$
PCR was done using $G$ mixturefrom FailSafe PCR System (EPICENTRE, Madison, WI, USA) and 2720 Thermal Cycler from Applied Biosystem (AB). PCR product were visualized using electrophoresis in 3\% agarose HS gel (Cambrex Bioscience, Rockland, ME, USA) withTBE (Tris/Boric-acid/EDTA, pH 8.0) buffer at 100 Volt.

\section{Results}

\section{Antibody-specific Responses to Mycobacterium leprae Phenolic Glycolipid-1}

Five hundred and thirty children, consisting of 301 students from elementary school in Pacitan and 229 students from Lamongan were registered and has clinically examined. In lamongan, from 229 students, $110(48,3 \%)$ students are seropositives, however in Pacitan, only 25 (8.3\%) out of 301 are positives (see Table 1).

The cut off value seropositivity of IgM antibody $\geq 605 \mathrm{U} / \mathrm{mLis}$ based on
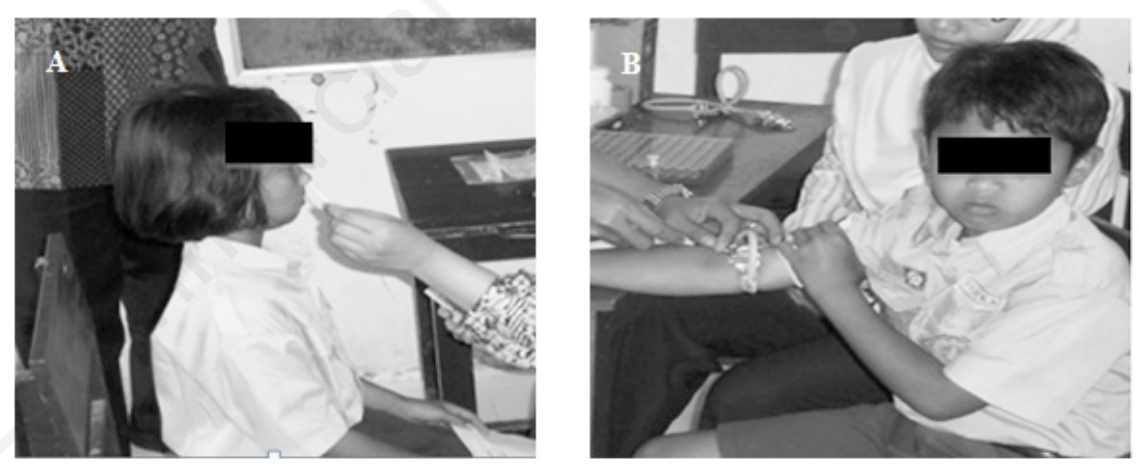

Figure 1. Field survey in the context of taking nasal swab (A) and blood (B) specimens in school children in endemic leprosy area in north coast (Lamongan District) and nonendemic leprosy area in south coast (Pacitan District).

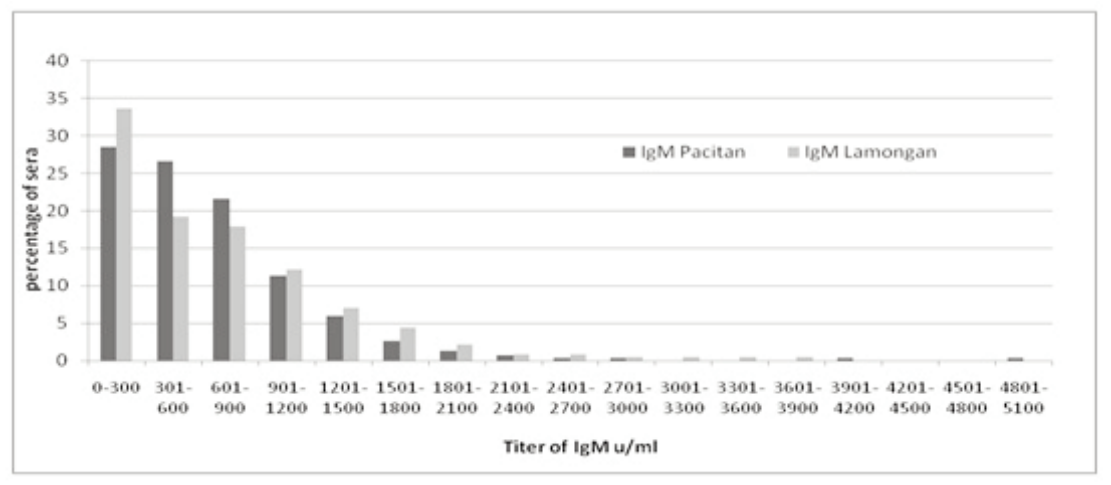

Figure 2. Distribution of serological level of IgM antibody anti PGL-1 among healthy children in endemic leprosy area in north coast (Lamongan District) and non-endemic leprosy area in south coast (Pacitan District). 
nasal swab and IgM antibody PGL-1 while in Pacitan, there are 6 cases $(6 / 301)$ positives. From the school children in Lamongan that have ELISA positivity, $39.9 \%$ (45/110) have contact with leprosy patients, while students that have PCR positivity, 59.2\% (29/49) have contact with leprosy patients (See Figure 4). However, students in Pacitan that both has ELISA and PCR positives, all have historical contact with leprosy patients. From all the results of the PCR and ELISA profiles from the two regions can be concluded, transmission of M. leprae, children who are in endemic areas are more likely to have risk to be infected with $M$. leprae at least 5 times at risk (relative risk/RR value 5.0386) than children who live in non-endemic areas (95\% CI 2.0859 to 12.1706 ; $\mathrm{P}<0.05$ ).

\section{Discussion}

Leprosy is known to occur at all ages ranging from early infancy to old age, most common in adult. Among children, the disease tends to occur with the highest frequency in 5-14 years of age group, only up to $6 \%$ cases below 5 years of age. In this study, we collect children with age of group between 9-13 years of age in each areas.

Most new cases detection rate of leprosy (NCDR) in Indonesia are found in East Java (3373/100.000 inhabitants), with the proportion of new leprosy in children around $8 \%$, this figure has not been decreasing during the period 2015-2017.4,13 The new cases finding in children and adolescents, which tends to be stable, show the active circulation of bacillus, with its continued transmission and the failure of the health system to control this disease. One of the most important sources of infection in childhood cases is familial contact with leprosy or called as household contact. ${ }^{14}$ In Lamongan, as described to be an endemic leprosy area, there is $39.9 \%$ IgM antibody positives to $M$. leprae, have a previous contact with the leprosy patients either because of neighbourhood or intra-familial contacts. It is almost the same condition in Pasuruan, another leprosy endemic area in East Java there is $29.9 \%$ school children with seropositivity of IgM anti PGL-1 has a historical contact with leprosy patients. ${ }^{15}$ According from the results, children who are in endemic areas are more likely to have risk to be infected with $M$. leprae at least 5 times at risk (relative risk/RR value 5.0386) than in non endemic areas (95\% CI 2.0859 to $12.1706 ; \mathrm{P}<0.05$ ).

Douglas $\mathrm{JT}^{16}$ monitored contacts over a period of 6 years and showed that there is a 7.2- fold greater risk of developing leprosy
(MB or $\mathrm{PB}$ ) in seropositive contacts with antibodies to PGL-1 when compared to seronegative contacts, increasing to 24-fold greater risk of developing MB leprosy. Raj et al ${ }^{17}$ found $43.33 \%$ sensitivity of PGL-1 in pediatric leprosy and found that percent-

age of contacts suggests that serology with anti-PGL-1 could be useful as a prognostic test. ${ }^{18}$ Environmental factor should be concerned as well, as one of reservoir and become source of infection for leprosy transmissionin endemic areas. According to

Table 1. ELISA positivity rate among healthy school children by geographic area.

\begin{tabular}{lccc} 
No of subject & \multicolumn{2}{c}{ FLISA positivity rate $^{a}$} \\
Lamongan & & No. & $\%$ \\
Pacitan & 229 & 110 & 48.3 \\
\hline Total & 301 & 25 & 8.3 \\
\hline
\end{tabular}

aStatistically significant difference between the two regions (chi-square test, $\mathrm{P}<0.05$ ).

Table 2. PCR positivity rate among healthy school children by geographic area

\begin{tabular}{lccc} 
Area & No of subject & No. & ELISA positivity rate $^{\mathrm{a}}$ \\
& & 49 & 21.4 \\
Lamongan & 229 & 9 & 2.9 \\
Pacitan & 301 & 58 & \\
\hline Total & 530 & 49 & \\
\hline
\end{tabular}

a Statistically significant difference between the two regions (chi-square test, $\mathrm{P}<0.05$ ).

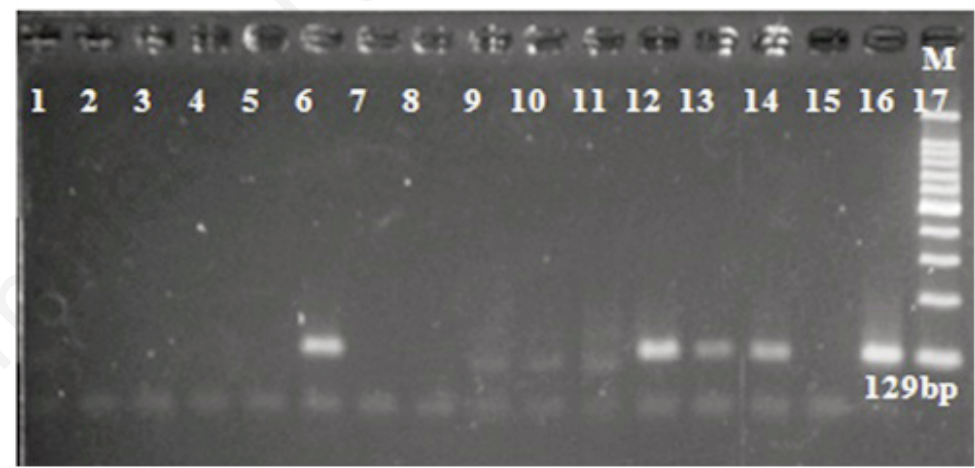

Figure 3. PCR amplification and detection of the 129-bp fragment of M.leprae DNA, visualized on 3\% agarose gel electrophoresis. Lane 17 is $100 \mathrm{bp}$ DNA Ladder (M). Lane 1-14 are amplicons of nasal mucosa samples from school children, lane 6, 12, 13, 14 are PCR positive samples, lane 15 is negative control (no DNA amplification), lane 16 is positive control (M.leprae Thai-53).

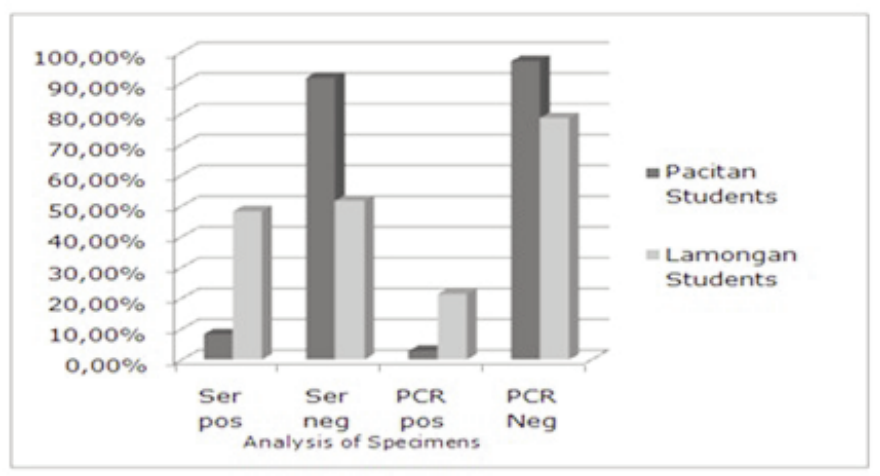

Figure 4. Distribution of seropositivity of IgM antibody and PGL-1 and PCR positivity in endemic leprosy area among healthy children in north coast (Lamongan District) and non-endemic leprosy area in south coast (Pacitan District). 
several research report that previous conducted in leprosy endemic areas in Indonesia such as Gresik, Sumenep, Lamongan shows that some DNA positives $M$. leprae founded in daily consumable water and tap water and the genotyping variation of $M$. leprae DNA detected from water, leprosy patients and household contacts and healthy inhabitants in that areas are the same. It can be resumed that environment, agent and host factor in leprosy endemic areas are related. ${ }^{19-21}$ Subclinical leprosy in children has to be concerned to become a potential source of infection in leprosy transmission as well, whether in endemic areas or import case in non leprosy endemic areas, although clinically not yet manifested as leprosy, it must be monitored and then should be given better treatment. Household contacts should be evaluated annually for evidence of disease for at least 5 years and should be educated to seek immediate attention if suspicious skin or neurologic changes develop. Hence, community education about leprosy along with mandatory household contact and school survey if implemented nationally would result in the reduction of disease burden. ${ }^{22}$

The most important thing to observe leprosy in children in leprosy endemic areas is, the prevention of disabilities and deformities by early detection and better treatment of leprosy. The selection of diagnostic tools to help clinical diagnosis is a major requirement for achieving zero disabilities among new pediatric leprosy patients by $2020 .^{23,24}$ Detection of $M$. leprae by newer methods on the nasal swab by PCR method and serological tests to see the immune response of specific $M$. leprae anti PGL-1 antibodies (molecular and serology diagnostic methods) is one way methods for early detection. Looking for simpler and faster kit is still need a further investigation, much less to do in Indonesia.

\section{References}

1. Narang T, Kumar B. Leprosy in Children. Indian $\mathrm{J}$ Pae Dermatol 2019;20(1):12-24.

2. WHO. Weekly epidemiological record. World Health Organization. Available from http://www.who.int/wer/en. Accessed: December 2018

3. Dinkesprov Jatim. Profil Kesehatan Provinsi Jawa Timur Tahun 2017.
2018.Dinas Kesehatan Provinsi Jawa Timur.Surabaya.

4. Kemenkes RI. InfoDatin Kusta. 2018. Kementerian Kesehatan RI. Jakarta.

5. Truman R, Fine PE. 'Environmental' Source of Mycobacterium leprae: Issues and Evidence. Lep Rev 2010;81:89-95.

6. WHO. Neglected Tropical Diseases, Leprosy: World Focused on Ending Transmission Among Children. World Health Organization.Available from: http//www.ws.who.int/neglected_diseases/news/leprosy_ending_transmission among children/en. Accessed: April 2018

7. Jadhav RS, Macdonald M, Bjune G, Oskam L. Simplified PCR Detection Method for Nasal Mycobacterium leprae. Int $\mathrm{J}$ Lepr Other Mycobact Dis 2001;69: 299-307.

8. Spencer JS, Kim HJ, Wheat WH, et al. Analysis of Antibody Responses to Mycobacterium leprae Phenolic Glycolipid I, Lipoarabinomannan, and Recombinant Proteins To Define Disease Subtype-Specific Antigenic Profiles in Leprosy. Clin Vacc Immun 2011;18:260-267.

9. Cho SN, Yanagihara DL, Hunter SW, et al. Serological specificity of phenolic glycolipid I from Mycobacterium leprae and use in serodiagnosis of leprosy. Infect. Immun. 1983; 41: 1077-1083.

10. Kemenkes RI. Pedoman Nasional Program Pengendalian Kusta.2014. Kementerian Kesehatan RI. Jakarta.

11. Donoghue HD, Holton J, Spigelman M. PCR Primers that can detect low levels of Mycobacterium leprae DNA. J Med Microbiol 2001;50:177-182.

12. Putri RD, Amiruddin MD, Farida T, et al. Evaluation of anti PGL-1 Antibody Titer in a group of Healthy School Children Who Live in Leprosy Endemic Area From 2007-2010. Indon J Trop Infec Dis 2010;1:110-113.

13. Firdaus F. The Risk of Late Treatment and The Reaction of Leprosy With Grade 2 Disability. JBE 2019;7:25-32.

14. Barreto JG, Guimaraes Lde S, Leao MR, et al. Anti-PGL-1 seroepidemiology in leprosy cases: household contacts and school children from a hyperendemic municipality of the Brazilian Amazon. Lepr Rev 2011; 82:358-70.

15. Iswahyudi. Factors that Influence The Incidence of Subclinical Leprosy Among Elementary School Children in
Watestani Area, Nguling, Subdistrict of Pasuruan, Indonesia. Thesis., Universitas Airlangga, Surabaya; 2012.

16. Douglas JT, Cellona RV, Fajardo TT, et al. Prospective study of serological conversion as a risk factor for development of leprosy among household contacts.nClin Diagn Lab Immunol, 2004;11:897-900.

17. Cellona RV, Walsh GP, Fajardo TT, et al. Cross-sectional assessment of ELISA reactivity in leprosy patients, contacts, and normal population using the semisynthetic antigen natural disaccharide octyl bovine serum albumin (ND-O-BSA) in Cebu, The Philippines. Int J Lepr Other Mycobact Dis. 1993; 61: 192-198.

18. Kamal R, Dayal R, Singh M, Mohanty KK. Evaluation of diagnostic role of IP10 (Interferon Gamma Inducible Protein) and anti PGL-1 antibody in pediatric leprosy. J Pediatr Res. 2017; 4:76-81.

19. Agusni I, Iswahyudi, Adriaty D, Izumi S. Study of Mycobacterium leprae from the natural environment in leprosy endemic areas. Maj Kedok Indon. 2004;54: 51-53.

20. Adriaty D, Wahyuni R, Iswahyudi, et al. TTC Repeats variation of Mycobacterium leprae isolates for analysis of leprosy transmission in leprosy endemic area of East Java. Indon J of Trop and Infect Dis. 2010;1:14-15.

21. Prakoeswa CRS, Herwanto N, Wahyuni $\mathrm{R}$, et al. Genotyping Analysis of Mycobacterium leprae isolated in water environment of leprosy endemic places in Lamongan, East Java. 2017. KnE Life Sciences. VMIC Conference: 356368.

22. Chaptini C, Marshman G. Leprosy: A review on elimination, reducing the disease burden and future research. Lepr Rev 2015; 86:307-315.

23. Prakash O. Serological detection of leprosy employing Mycobacterium leprae derived serine-rich $45 \mathrm{kDa}$, ESAT-6, CFP-10 and PGL-1: A compilation of data from studies in Indian populations. Lepr Rev 2011; 82:383-8.

24. Kamal R, Dayal R, Katoch VM, Katoch $\mathrm{K}$. Analysis of geneprobes and gene amplification techniques for diagnosis and monitoring of treatment in childhood leprosy. Lepr Rev 2006; 77:141146. 